HYPOXIA AND REPRODUCTIVE HEALTH

\title{
Hypoxic regulation of preimplantation embryos: lessons from human embryonic stem cells
}

\author{
Franchesca D Houghton \\ Centre for Human Development, Stem Cells \& Regeneration, School of Human Development and Health, Faculty of \\ Medicine, University of Southampton, Southampton, UK
}

Correspondence should be addressed to F D Houghton; Email: F.D.Houghton@soton.ac.uk

This paper forms part of a special section on Hypoxia and Reproductive Health. The guest editor for this section was Dr Jacqueline Maybin (University of Edinburgh, UK)

\begin{abstract}
Development of the preimplantation embryo is reliant on nutrients present in the milieu of the reproductive tract. While carbohydrates, amino acids, lipids, and micronutrients are often considered when discussing preimplantation embryo nutrition, environmental oxygen is frequently overlooked. Although oxygen is not classically considered a nutrient, it is an important component of the in vitro culture environment and a critical regulator of cellular physiology. Oxygen is required to sustain an oxidative metabolism but when oxygen becomes limited, cells mount a physiological response driven by a family of transcription factors termed 'hypoxia inducible factors' which promote expression of a multitude of oxygen sensitive genes. It is this hypoxic response that is responsible not only for the switch to a glycolytic metabolism but also for a plethora of other cellular responses. There has been much debate in recent years over which environmental oxygen tension is preferential for the culture of preimplantation embryos. The review will evaluate this question and highlights how research using human embryonic stem cells can inform our understanding of why culturing under physiological oxygen tensions may be beneficial for the development of embryos generated through clinical in vitro fertilisation.

Reproduction (2021) 161 F41-F51
\end{abstract}

\section{Oxygen environment in the reproductive tract}

Oxygen is essential for mammalian life and although the atmosphere contains $160 \mathrm{mmHg}$ oxygen at sea level, or approximately $20.9 \%$ oxygen, the concentration present in different tissues within the body varies widely but are much lower in the range of $5-100 \mathrm{mmHg}$ (Ast \& Mootha 2019). In vivo, the preimplantation embryo develops in an increasingly hypoxic environment (Fig. $1) ; \sim 8.7 \%$ oxygen in the oviduct decreasing to $1.5-2 \%$ oxygen in the uterus of the rhesus monkey (Fischer \& Bavister 1993) while in the human, the intrauterine oxygen tension is $\sim 2 \%$ oxygen (Ottosen et al. 2006). This dramatic reduction in oxygen tension as the embryo reaches the uterus is perhaps not surprising given that the implantation site in the rat uterus is devoid of blood vessels and hence thought to be anoxic (Rogers et al. 1983). Given the hypoxic environment of the reproductive tract, exposure of embryos to supraphysiological oxygen tensions in incubators maintained at $5 \% \mathrm{CO}_{2}$ in air must be questioned.

There has been much debate over the nomenclature used to describe the oxygen tension in the female reproductive tract. This is because the low, $1.5-8.7 \%$ oxygen environment experienced by the preimplantation embryo in vivo is clearly physiological and hence would more accurately be described as normoxic, rather than hypoxic. Indeed, it would then follow that atmospheric oxygen should be classed as hyperoxic for the preimplantation embryo in vitro. However, convention in the field uses atmospheric, or $20 \%$ oxygen to describe normoxia, with a reduced oxygen tension with respect to atmospheric oxygen being termed hypoxia. Thus, for the purpose of this review, conventional terminology will be used but with particular care taken to avoid use of the term 'normoxia'. Instead, the oxygen tension experienced in the reproductive tract will be termed physiological, or hypoxic and compared to atmospheric, or $20 \%$ oxygen.

\section{Effect of oxygen tension on the preimplantation embryo}

The first reports demonstrating the beneficial effect of culturing mouse embryos at 5\% oxygen were published by Whitten $(1969,1971)$. In agreement with these studies, 


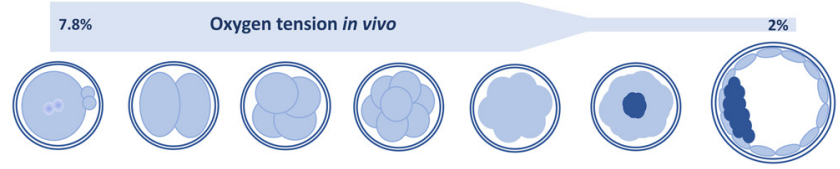

Figure 1 Schematic representation of the oxygen tension in the reproductive tract during preimplantation development.

not only did more 2-cell mouse embryos develop to the blastocyst stage when cultured at 5\% oxygen compared to 20 or $40 \%$ oxygen, but culture at atmospheric oxygen was also associated with a lower cell count in blastocysts compared to embryos cultured at 5\% oxygen (Quinn \& Harlow 1978, Harlow \& Quinn 1979). It became apparent that not only the concentration of oxygen used, but also the stage at which the embryo is exposed to different oxygen levels is important. Exposure of pronucleate mouse embryos to atmospheric oxygen for just $1 \mathrm{~h}$ before culturing to the blastocyst stage at $5 \%$ oxygen was found to inhibit development past the morula stage compared to continual culture at 5\% oxygen (Pabon et al. 1989). Although continual culture of mouse zygotes at either 5 or $20 \%$ oxygen did not affect compaction or blastocyst rates, exposure to atmospheric oxygen caused a significant reduction in the number of inner cell mass (ICM) cells, and a reduction in fetal development per blastocyst transferred compared to culture under hypoxic conditions (Karagenc et al. 2004). This study highlights the importance of in vivo studies to fully elucidate the effect that perturbations during the preimplantation stages can have on subsequent embryo development.

Recently, the effect of culturing mouse embryos in the sequential oxygen environment observed in vivo was investigated (Nguyen et al. 2020). Embryos cultured at $7 \%$ oxygen from day 1 to day 3 followed by $2 \%$ from day 3 to day 5 displayed a significant increase in the rate of blastocyst formation and accelerated cell divisions at several stages of preimplantation development compared to those cultured at either 5 or $20 \%$ oxygen (Nguyen et al. 2020). This suggests that mimicking the oxygen levels found in the oviduct and uterus may be beneficial, but blastocyst transfer studies are required to determine any impact on implantation and subsequent development.

It is also important to remember that the effect environmental oxygen tension exerts on the preimplantation embryo may be influenced by other variables in the culture system. For example, consideration should be given to whether embryos are cultured individually, or in groups. Compared to mouse embryos cultured at $5 \%$ oxygen in groups, there was a sequential reduction in the day 5 blastocyst cell number and hatching rate for embryos cultured individually at $5 \%$ oxygen, in groups at $20 \%$ oxygen or individually at $20 \%$ oxygen (Kelley \& Gardner 2016). Upon transfer of blastocysts to pseudopregnant recipients, although individual culture at $5 \%$ oxygen did not affect placental or fetal development, the placental labyrinth area was reduced compared to group culture at 5\% oxygen. However, when culture at $20 \%$ was investigated, placental weight, fetal weight, crown-rump length and fetal weight to length ratio were all decreased when embryos were cultured individually compared to group culture (Kelley \& Gardner 2019). Similarly, medium composition can alter the effect of environmental oxygen on the embryo. In the bovine, embryo development to the blastocyst stage was improved by culturing at 5\% oxygen compared to $20 \%$ oxygen (Fujitani et al. 1997). However, the addition of hypotaurine increased the rate of blastocyst formation at both $5 \%$ oxygen and at $20 \%$ oxygen (Fujitani et al. 1997). Together, these studies suggest that although culture at $5 \%$ oxygen was beneficial compared to $20 \%$ oxygen, the magnitude of the effect is dependent on other variables of the culture system and highlights the importance of optimising each individual component of the culture environment. Variation in media and culture components, together with heterogeneity of gamete sources and animal breeds may explain why some studies report no beneficial effects of culture at low oxygen tensions (Bahçeci et al. 2005), or even improved development at atmospheric oxygen tensions (Fischer-Brown et al. 2002, Mingoti et al. 2011).

Over the years, the benefit of culturing preimplantation embryos under hypoxic conditions has been shown in numerous species including the bovine (Thompson et al. 1990, Lim et al. 1999, Olson \& Seidel 2000), porcine (Berthelot \& Terqui 1996, Karja et al. 2004, Kitagawa et al. 2004), ovine (Thompson et al. 1990, Bernardi et al. 1996) and leporine (Li \& Foote 1993) but what about the human embryo?

It should be remembered that $5 \%$ oxygen has been used to culture embryos since the inception of human in vitro fertilisation (IVF) (Edwards et al. 1970, Steptoe et al. 1971, Steptoe \& Edwards 1978). Initial studies comparing the culture of human embryos at either 5 or $20 \%$ oxygen before transfer at $42-46 \mathrm{~h}$ post-insemination found no difference in the rate of fertilisation, implantation or pregnancy (Dumoulin et al. 1995). Similar results were obtained in a prospective randomised study when embryos were cultured for 2 or 3 days at either 5 or $20 \%$ oxygen (Dumoulin et al. 1999). However, surplus embryos cultured at $5 \%$ oxygen were found to have an increased rate of blastocyst formation and cell number than those cultured at 20\% oxygen (Dumoulin et al. 1999) suggesting that a reduced oxygen tension becomes increasingly important as the embryo develops. The fact that culturing embryos at 20\% oxygen until the cleavage stage, before transfer to the uterus had no deleterious effect on the rate of implantation was intriguing and it is tempting to speculate that the hypoxic environment present in vivo after transfer, provides a more favourable 
milieu for the embryo to complete compaction and undergo cavitation.

Two independent, prospective studies both using sibling human oocytes demonstrated that hypoxic culture did not affect fertilisation rates. However, the rate of blastocyst formation and the quality of blastocysts produced on day 5 of development was significantly improved when cultured at $5 \%$ compared to $20 \%$ oxygen throughout development (Kovacic \& Vlaisavljevic 2008, Ciray et al. 2009). These studies suggest that, in contrast to animal studies, the human early cleavage stage embryo may either be less sensitive to oxygen toxicity than the later stages of preimplantation development, or that perturbations acquired early in development are not manifest until the blastocyst stage. Investigating blastocyst formation is important but the ultimate clinical outcome is live birth rates. In a randomised controlled trial where gametes and embryos were cultured at either 5 or $20 \%$ oxygen and transferred on day $2-3$ or day 5 , livebirth implantation rate (number of live births divided by the number of embryos transferred), or the live birth rate (number of patients with at least one live born infant compared to the number of patients who had an oocyte retrieved) were measured as the primary endpoints (Meintjes et al. 2009). Oxygen tension had no effect on these parameters when embryos were transferred at the early cleavage stages. However, when embryos were cultured under hypoxic conditions and transferred at the blastocyst stage there was a dramatic increase in the livebirth implantation rate and the clinical pregnancy rate compared to those cultured at $20 \%$ oxygen. When the data for day 2-3 and day 5 transfers were combined, culture at 5\% oxygen showed a significantly improved livebirth implantation rate and live birth rate (Meintjes et al. 2009). Similarly, more recent data have shown that culture at either 5 or $20 \%$ oxygen until day 2 or day 3 before transfer had no effect on the live birth rate per cycle but hypoxic culture did result in more good quality embryos for cryopreservation following transfer (Van Montfoort et al. 2020). Together, these data highlight the importance of hypoxic culture particularly when performing blastocyst transfers or cryopreserving human embryos.

The majority of studies have compared culture at $5 \%$ oxygen with $20 \%$ oxygen but the uterine environment has a much lower oxygen tension than the fallopian tube. Hence, would culture at 5\% oxygen for the first 3 days of development, followed by $2 \%$ oxygen be more physiological and beneficial for blastocyst formation? This precise question was investigated in two separate human studies (Kaser et al. 2018, De Munck et al. 2019). The first study using bi-pronucleate and tri-pronucleate embryos showed improved cleavage and blastocyst formation by the dual culture regime but reduced blastocyst cell number compared with continual 5\% oxygen (Kaser et al. 2018). The second study found no difference in cavitation rate or the proportion of good quality blastocysts between the two (De Munck et al. 2019). Thus, it appears that $\%$ oxygen from day 3 to the blastocyst stage does not improve embryo quality above that already observed by $5 \%$ oxygen. However, there are a couple of caveats; neither of these studies looked at development beyond the blastocyst stage and therefore implantation or livebirth rates may still be affected. Also, moving embryos from $5 \%$ oxygen to $2 \%$ oxygen on day 3 may be developmentally early and perhaps day 4 might be preferential to ensure the embryo is at the morula stage, where in vivo, it would be located in the uterus.

There has now been a plethora of reports, including a Cochrane systematic review showing improved embryo development and clinical outcomes for human embryos cultured under hypoxic as opposed to atmospheric oxygen conditions (Bontekoe et al. 2012, Kasterstein et al. 2013, Kirkegaard et al. 2013, Guo et al. 2014, Ruiz et al. 2020).

\section{Why is a low oxygen tension beneficial for preimplantation development?}

Understanding how physiological oxygen tensions regulate embryo development is an area of active research and has been summarised in Fig. 2. The functional significance of a hypoxic reproductive tract may be to protect the blastocyst from the detrimental effects of reactive oxygen species (ROS) since embryos cultured at $5 \%$ oxygen produce less ROS than those cultured at 20\% oxygen (Goto et al. 1993, Leite et al. 2017). This is important since ROS causes DNA damage, induction of apoptosis and lipid peroxidation (Takahashi 2012) and has been shown to be deleterious to development in the murine (Cebral et al. 2007, Ma et al. 2017), bovine (Takahashi et al. 2000) and human (Bedaiwy et al. 2004, 2010) embryo.

Environmental oxygen can also impact cellular senescence, a phenomenon where cells undergo persistent arrest but remain viable and able to secrete soluble factors which influence surrounding cells (Childs et al. 2014). Mouse blastocysts cultured at 5\% oxygen displayed significantly lower levels of senescence-

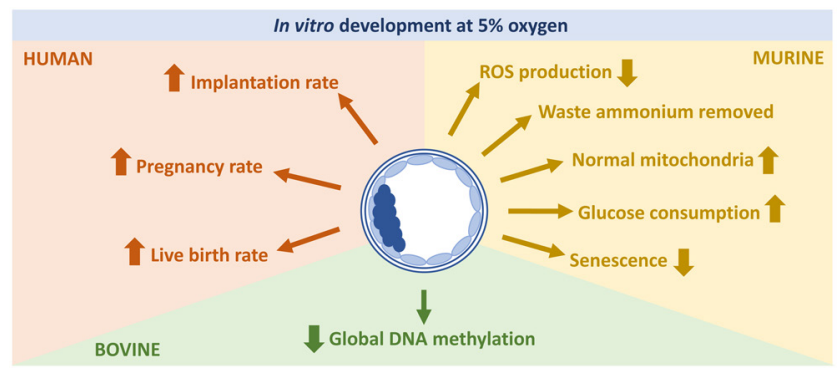

Figure 2 Schematic representation of the beneficial effects of culturing preimplantation embryos to the blastocyst stage at 5\% oxygen compared to atmospheric oxygen. 
associated $\beta$-galactosidase (SA- $\beta$-galactosidase) and phosphorylated histone H2A.X, a protein associated with DNA damage than those cultured at atmospheric oxygen (Meuter et al. 2014). These results are intriguing and suggest that environmentally induced stressors, such as $20 \%$ oxygen can induce senescence in embryos.

Oxygen tension is intrinsically linked to metabolism and the generation of ATP. It has long been known that mitochondria are immature, spherical in shape, contain few cristae with a proportion being vacuolated during early mouse embryo development (Hillman \& Tasca 1969). In contrast, by the blastocyst stage, mitochondria within the trophectoderm are slender and contain prominent cristae whereas in the ICM, they remain spherical and immature (Stern et al. 1971). This results in the trophectoderm being metabolically energetic, consuming more oxygen, producing more ATP and possessing more active mitochondria than the quiescent ICM (Houghton 2006). The precise mechanisms which regulate mitochondrial development in the embryo remain to be discovered but environmental oxygen has been shown to be involved (Belli et al. 2019). Mouse IVF embryos cultured at $20 \%$ oxygen contained fewer normal mitochondria and more vacuoles compared to those cultured at $5 \%$ oxygen, or in vivo produced embryos (Belli et al. 2019). Further research is required to understand the mechanisms regulating these results but the authors' suggestion that atmospheric oxygen may alter mitochondrial division, leading to an abnormal morphology and a reduction in total mitochondrial number warrants further investigation. This hypothesis would also be supported by work in astrocytes where exposure to hypoxia for $3 \mathrm{~h}$ caused an increase in mitochondrial number compared to $20 \%$ oxygen (Quintana et al. 2019).

Metabolism is integral for embryo survival. The preimplantation embryo displays remarkable plasticity in terms of energy metabolism often being able to adapt and utilise whichever nutrients are present in the culture medium. For example, human embryos will develop to the blastocyst stage in a simple medium (Conaghan et al. 1998), but the addition of amino acids enhances development (Devreker et al. 2001). During the cleavage stages, mouse embryos consume pyruvate whereas at compaction glucose becomes the predominant energy substrate utilised (Martin \& Leese 1999). Environmental oxygen has also been shown to alter embryo metabolism. When mouse embryos were cultured at 5\% oxygen during the cleavage stages, they consume less amino acids and pyruvate than those cultured at atmospheric oxygen. In contrast, when post-compaction embryos were cultured at $5 \%$ oxygen, amino acid and glucose consumption was increased compared to those cultured at $20 \%$ oxygen (Wale \& Gardner 2012). As hypoxic culture was associated with a significantly increased rate of blastocyst formation and cell number, it suggests that metabolism may be associated with developmental competency and be regulated by oxygen tension.

Ammonium is a waste product of amino acid metabolism and toxic to preimplantation embryos (Lane \& Gardner 1994). Thus, it is important that ammonium is sequestered to facilitate development. Mouse blastocysts are able to alleviate ammonium via transamination to glutamine and alanine but interestingly, only when cultured under hypoxic conditions and not at atmospheric oxygen tensions (Wale \& Gardner 2013). These findings were intriguing but provide further metabolic support for culturing embryos at a reduced oxygen tension.

Perhaps some of the most compelling data to support the culture of preimplantation embryos under hypoxic conditions looked at global gene (Rinaudo et al. 2006) and protein (Katz-Jaffe et al. 2005) expression of blastocysts. Mouse blastocysts cultured from the zygote stage at $5 \%$ oxygen displayed a similar global gene expression pattern to that of in vivo derived blastocysts. In contrast, embryos cultured at $20 \%$ oxygen displayed a decreased blastocyst cell number and a global gene expression pattern more disparate to that of in vivo blastocysts (Rinaudo et al. 2006). Similar results were obtained at the proteome level; mouse blastocysts cultured at $5 \%$ oxygen exhibited a protein expression profile more similar to in vivo derived blastocysts, while the proteome of blastocysts cultured at atmospheric oxygen was more divergent (Katz-Jaffe et al. 2005). These papers provide unequivocal evidence to support the culture of preimplantation embryos at $5 \%$ oxygen, at least in the mouse.

Environmental oxygen is also able to modulate the epigenetic status of the embryo. In bovine embryos, atmospheric oxygen was found to increase global DNA methylation at both the 4-cell and blastocyst stage compared to 5\% oxygen ( $\mathrm{Li}$ et al. 2016). Similarly, the gene expression of lysine-specific histone demethylases (KDMs), specifically KDM1 A, KDM4B and KDM4C were decreased in bovine blastocysts cultured at atmospheric oxygen compared to 5\% oxygen (Skiles et al. 2018) suggesting that environmental oxygen also alters the chromatin landscape of the embryo.

\section{Regulation of oxygen homeostasis}

It is clear that atmospheric oxygen is deleterious for embryo development and while many physiological processes have been shown to be affected, the question remains; how is oxygen homeostasis in development regulated? Under conditions of low oxygen tension, cells mount a physiological response regulated by a family of transcription factors called hypoxic inducible factors (HIFs) which ensure oxygen homeostasis is maintained for critical oxygen-dependent processes. HIFs are known to regulate many hundreds of genes including those involved in energy metabolism, 
apoptosis, proliferation, self-renewal and vasculogenesis (Carmeliet et al. 1998, Ramírez-Bergeron et al. 2006, Goda \& Kanai 2012, Petruzzelli et al. 2014). HIFs form a heterodimeric complex consisting of an oxygendependent alpha subunit, either HIF1A, HIF2A or HIF3A, and the constitutively expressed beta subunit, HIF1B (also known as ARNT - aryl hydrocarbon receptor nuclear translocator). When oxygen is in a plentiful supply, HIF alpha subunits are hydroxylated by proline hydroxylases, recognised by the von HippelLindau protein and ubiquitin ligase complex, and targeted for degradation by the proteasome. In contrast, when oxygen supply is limited the HIF alpha subunits can no longer be hydroxylated by proline hydroxylases, are stabilised and translocate to the nucleus where they bind to the HIF1B subunit. HIFs bind to a conserved consensus sequence (A/G)CGTG termed a hypoxic response element (HRE) in the proximal promoter or enhancer of hypoxia regulated genes and increase transcription (Semenza \& Wang 1992). HIF1A was the first discovered, is ubiquitously expressed and hence was considered to be the master regulator of the hypoxic response (Wang et al. 1995, Semenza 1998). HIF2A (also known as EPAS1) was first characterised by three independent groups (Ema et al. 1997, Tian et al. 1997, Flamme et al. 1998) and found to be structurally similar to HIF1A having a $48 \%$ amino acid homology ( $\mathrm{Hu}$ et al. 2003). However, in comparison to HIF1A, HIF2A has a more restricted pattern of expression including vascular endothelial cells, liver parenchymal cells and renal interstitial cells (Tian et al. 1997, Wiesener et al. 2003). Although HIF1A and HIF2A bind to the same HRE, HIF1A is thought to be responsible for the initial, acute transcriptional response to hypoxia, while HIF2A regulates the chronic hypoxic response (HolmquistMengelbier et al. 2006, Mole et al. 2009, Koh et al. 2011). HIF3A, or IPAS has a limited pattern of expression including thymus, corneal epithelium and Purkinje cells of the cerebellum (Gu et al. 1998, Makino et al. 2001). It is the least well characterised of the HIF alpha subunits and has multiple splice variants which have been shown to inhibit HIF1A and HIF2A (Gu et al. 1998, Hara et al. 2001, Heikkila et al. 2011).

HIFs are crucial for embryo development. Both HIF1A and HIF2A null mice are embryonic lethal. HIF1A-/mice die around day E11 with vascular defects, the neural tube fails to close due to mesenchymal cell death and there are also cardiovascular malformations (lyer et al. 1998, Kotch et al. 1999). HIF2A-/- mice die around day E12.5-E16.5 from bradycardia (Tian et al. 1998). In some cases, HIF2A null mice die shortly after birth from respiratory distress syndrome (Compernolle et al. 2002). Interestingly, loss of HIF2A was also found to dramatically decrease the number of primordial germ cells present in E8.5 embryos (Covello et al. 2006).

In the bovine blastocyst, the mRNA expression of both HIF1A and HIF2A was unaffected by environmental oxygen. However, in embryos cultured at $7 \%$ oxygen before compaction and then transferred to either 2, 7 or $20 \%$ oxygen, HIF1A protein was not expressed in any of the blastocysts. In contrast, HIF2A protein was expressed predominantly in the nuclei of blastocysts cultured in each treatment group but expression appeared increased in the ICM of blastocysts cultured at $2 \%$ oxygen post-compaction compared to $7 \%$ oxygen (Harvey et al. 2004). Interestingly, the number of cells in the ICM were significantly increased in the bovine blastocysts cultured at $2 \%$ oxygen compared to those cultured at 7 or $20 \%$ oxygen post-compaction despite there being no overall difference in total blastocyst cell number (Harvey et al. 2004). Intriguingly, culture at $2 \%$ oxygen post-compaction was also associated with an increase in GLUT1 (Harvey et al. 2004) and lactate dehydrogenase A (Harvey et al. 2007) mRNA. Both GLUT1 (Petruzzelli et al. 2014) and lactate dehydrogenase A (Cui et al. 2017) have been shown to be target genes for HIF2A and hence may be responsible for their increased expression. More recently, HIF2A was observed predominantly in the nuclei of mouse blastocysts cultured from the 2 -cell stage at $3 \%$ oxygen, whereas those cultured at $20 \%$ oxygen displayed only very weak cytoplasmic staining (Ma et al. 2017). These investigators also found increased GLUT3 and VEGF transcript expression in blastocysts cultured under hypoxic as opposed to atmospheric oxygen. Again, both GLUT3 and VEGF are known to be HIF regulated (Maxwell et al. 1997). It is tempting to speculate that HIF2A may be responsible for the increased glucose uptake (Wale \& Gardner 2012) observed under hypoxic conditions by enhancing the expression of GLUT1, GLUT3 and lactate dehydrogenase A. Similarly, the increased VEGF expression under hypoxia may stimulate angiogenesis required at implantation. However, caution must be exercised as the increase in these genes were observed at the mRNA level and further work is required to determine whether there is a concomitant increase in protein expression.

\section{Importance of oxygen homeostasis - lessons from embryonic stem cells}

Embryonic stem cells (ESCs) derived from the ICM of the blastocyst have the characteristics of self-renewal and pluripotency, the ability to give rise to cells of all three germ lineages. Being able to differentiate into all cells of the body, they hold great potential for regenerative medicine and the treatment of degenerative disorders. Human ESCs (hESCS) are notoriously difficult to maintain in vitro as they have a propensity to differentiate, likely due to a suboptimal culture environment. Like the preimplantation embryo, there are numerous reports of the beneficial effects of culturing hESCs under hypoxic conditions. These include a reduction in chromosomal abnormalities and enhanced clonal efficiency 
(Forsyth et al. 2006), protection against spontaneous differentiation (Ezashi et al. 2005, Prasad et al. 2009), increased proliferation (Ludwig et al. 2006, Forristal et al. 2010), enhanced expression of key transcription factors which regulate self-renewal, namely OCT4, SOX2 and NANOG (Ludwig et al. 2006, Forristal et al. 2010, 2013, Petruzzelli et al. 2014), reduced oxygen consumption, greater consumption of glucose and production of lactate and thus an increased rate of flux through glycolysis (Forristal et al. 2013, Harvey et al. 2016), and a greater turnover of amino acids (Christensen et al. 2014) compared to cells maintained at atmospheric oxygen tensions. In addition, the derivation and culture of hESCs under physiological oxygen $(5 \%$ oxygen) has been shown to allow the retention of two active $X$ chromosomes, representing the ground state of pluripotency whereas exposure to $20 \%$ oxygen induced $X$ chromosome inactivation (Lengner et al. 2010). The efficiency of reprogramming somatic cells to induced pluripotent stem cells is also improved under hypoxic conditions (Yoshida et al. 2009). Together, these data suggest that maintenance of the pluripotent state is improved under hypoxia.

The mechanisms which regulate the beneficial effects of maintaining hESCs under hypoxia are beginning to be unravelled and HIFs have a central role. HIF1A was found to be responsible for regulating the initial hypoxic response. Upon exposure to hypoxia, HIF1A was located in the nucleus of hESCs and remained for $\sim 48 \mathrm{~h}$ but was absent following long-term culture under hypoxic conditions. In contrast, hESCs express HIF2A in the cytoplasm under atmospheric oxygen and for the first $48 \mathrm{~h}$ of hypoxia. However, following three passages under hypoxia, HIF2A protein had translocated to the nucleus to regulate the long-term hypoxic response (Forristal et al. 2010). Thus, although HIF1A is important for regulating the initial hypoxic response in hESCs, HIF2A drives the chronic response to hypoxia.

Under conditions of hypoxia, HIF2A promotes the self-renewal of hESCs by binding directly to an HRE in the proximal promoters of OCT4, SOX2 and NANOG to enhance their expression (Covello et al. 2006, Petruzzelli etal. 2014). hESCs possess bivalent chromatin comprising both active and silencing histone modifications. This ensures that although developmental genes are silenced, they are poised for activation (Bernstein et al. 2006). The hypoxic culture of hESCs was found to be associated with an altered histone modification profile around the HRE site in the proximal promoters of OCT4, SOX2 and NANOG. hESCs cultured at atmospheric oxygen contained high levels of H3K9me3, a marker of gene repression and significantly reduced $\mathrm{H} 3 \mathrm{~K} 4 \mathrm{me} 3$ and $\mathrm{H} 3 \mathrm{~K} 36 \mathrm{me} 3$, markers of gene activation around the HRE sites of NANOG and SOX2 compared to hESCs maintained at $5 \%$ oxygen. In contrast, the proportion of H3K36me3 was dramatically increased at the HREs of OCT4, SOX2 and NANOG in hESCs cultured at 5\% compared to $20 \%$ oxygen (Petruzzelli et al. 2014). These data suggest that hESCs maintained under hypoxic conditions are more euchromatic, allowing transcription factors and chromatin remodelling factors to bind whereas culture at atmospheric oxygen is associated with a more heterochromatic state.

hESCs have a metabolism based on glycolysis. Compared to atmospheric oxygen, under hypoxic conditions, hESCs consume more glucose and produce

Table 1 Effects of culturing preimplantation embryos in either a hypoxic or atmospheric oxygen tension.

\begin{tabular}{|c|c|c|c|}
\hline & \multicolumn{2}{|c|}{ Environmental oxygen tension } & \\
\hline & $5 \%$ & $20 \%$ & \\
\hline Mouse blastocyst ROS production & Lower & Higher & Goto et al. (1993) \\
\hline $\begin{array}{l}\text { Number normal mitochondria in mouse } \\
\text { IVF embryos }\end{array}$ & Higher & Lower & Belli et al. (2019) \\
\hline Mouse blastocyst senescence & Lower & Higher & Meuter et al. (2014) \\
\hline $\begin{array}{l}\text { Mouse pre-compaction amino acid } \\
\text { consumption }\end{array}$ & Lower & Higher & Wale \& Gardner (2012) \\
\hline $\begin{array}{l}\text { Mouse pre-compaction pyruvate } \\
\text { consumption }\end{array}$ & Lower & Higher & Wale \& Gardner (2012) \\
\hline $\begin{array}{l}\text { Mouse post-compaction glucose } \\
\text { consumption }\end{array}$ & Higher & Lower & Wale \& Gardner (2012) \\
\hline $\begin{array}{l}\text { Removal of waste ammonium by mouse } \\
\text { blastocysts }\end{array}$ & Yes & No & Wale \& Gardner (2013) \\
\hline Mouse blastocyst global gene expression & Similar to in vivo & Disparate to in vivo & Rinaudo et al. (2006) \\
\hline $\begin{array}{l}\text { Mouse blastocyst global } \\
\text { protein expression }\end{array}$ & Similar to in vivo & Disparate to in vivo & Katz-Jaffe et al. (2005) \\
\hline $\begin{array}{l}\text { Bovine blastocyst global DNA } \\
\text { methylation }\end{array}$ & Lower & Higher & Li et al. (2016) \\
\hline Human fertilisation rate & No difference & No difference & $\begin{array}{l}\text { Dumoulin et al. (1995), (1999), Kovacic \& Vlaisavljevic } \\
\text { (2008), Ciray et al. (2009), Kasterstein et al. (2013) }\end{array}$ \\
\hline Human implantation rate & Higher & Lower & Kasterstein et al. (2013), Ruiz et al. (2020) \\
\hline Human pregnancy rate & Higher & Lower & Kasterstein et al. (2013) \\
\hline $\begin{array}{l}\text { Human live birth rate per embryo } \\
\text { transferred }\end{array}$ & Higher & Lower & Meintjes et al. (2009), Kasterstein et al. (2013), Ruiz et al. (2020) \\
\hline
\end{tabular}


more lactate leading to an increased rate of flux through glycolysis. In contrast, oxygen consumption, the best global indication of the ability of a cell to produce ATP is decreased. These metabolic changes under hypoxia correlate with an increased expression of OCT4, SOX2 and NANOG and suggest that environmental oxygen regulates energy metabolism which is intrinsically linked to the self-renewal of hESCs (Forristal et al. 2013). This finding was subsequently supported by the observation that naïve hESCs which more closely represent cells of the ICM, exhibit an increased glycolytic flux compared to primed hESCs (more akin to epiblast stem cells) and that a decrease in glycolysis reduces the self-renewal of naïve hESCs (Gu et al. 2016).

Glucose is transported into hESCs through GLUT3 which is located in cell membranes, rather than via GLUT1, which displays a largely cytoplasmic localisation. GLUT3 expression was upregulated in hESCs under hypoxia and silencing GLUT3 decreased both glucose uptake and lactate production but interestingly, also reduced the expression of OCT4. Further analysis revealed a significant positive correlation between GLUT3 and OCT4 expression suggesting that hESC self-renewal is regulated by the rate of glucose uptake (Christensen et al. 2015). Together, these findings were intriguing, but the question remained, How does glucose metabolism regulates hESC self-renewal under hypoxia? This question was addressed with the use of glycolytic inhibitors; 2-deoxyglucose which competes with glucose for binding hexokinase, and 3-bromopyruvate which inhibits hexokinase through alkylation. When hESCs were cultured under hypoxic conditions in the presence of either of these inhibitors, as expected, the rate of lactate production was decreased, the mRNA expression of a panel of differentiation markers were increased and OCT4, SOX2 and NANOG protein expression decreased. However, surprisingly HIF- $2 \alpha$ expression was also significantly decreased (Arthur et al. 2019). This suggests that under hypoxia, glycolysis promotes hESC self-renewal through HIF- $2 \alpha$. HIF- $2 \alpha$ can then bind the proximal promoters of OCT4, SOX2 and NANOG to enhance expression and thus the selfrenewal of hESCs (Arthur et al. 2019). How glycolysis regulates HIF- $2 \alpha$ expression in hESCs remains to be determined but the mechanism is likely to be complex since HIF-2 $\alpha$ itself is also known to promote glycolysis through the increased expression of GLUT transporters (Forristal et al. 2013).

\section{Conclusions and future perspectives}

There is now overwhelming data to support the culture of preimplantation embryos under a reduced oxygen tension (Table 1). In the human, it appears that a hypoxic environment is particularly important for the later stages of preimplantation development, from compaction through to blastocyst formation. Originally, culturing embryos under low oxygen tensions were unwieldy, requiring pre-mixed gas cylinders containing $5 \% \mathrm{O}_{2}, 5 \% \mathrm{CO}_{2}$ and $90 \% \mathrm{~N}_{2}$ and desiccators, or sealed chambers. With the development of incubators capable of regulating oxygen tensions, cost became a barrier to implementing the culture of embryos at reduced oxygen tensions. However, with the accessibility of commercially available incubators that accurately regulate reduced oxygen tension, prices have become more affordable. Thus, it must be questioned why some IVF clinics continue to culture embryos under atmospheric oxygen; particularly those performing blastocyst transfers.

Data from hESCs may provide critical insight into why hypoxic conditions are beneficial for preimplantation embryos and particularly from compaction onwards in clinical IVF. Compaction is the stage where differential cell division occurs generating inner cells destined to become the ICM and outer cells which will give rise to the trophectoderm of the blastocyst. A mathematical model found that human morula cultured in static drops at $5 \%$ oxygen would be mildly hypoxic (Byatt-Smith et al. 1991). The authors recommended stirring to increase oxygen availability and hence development. On the

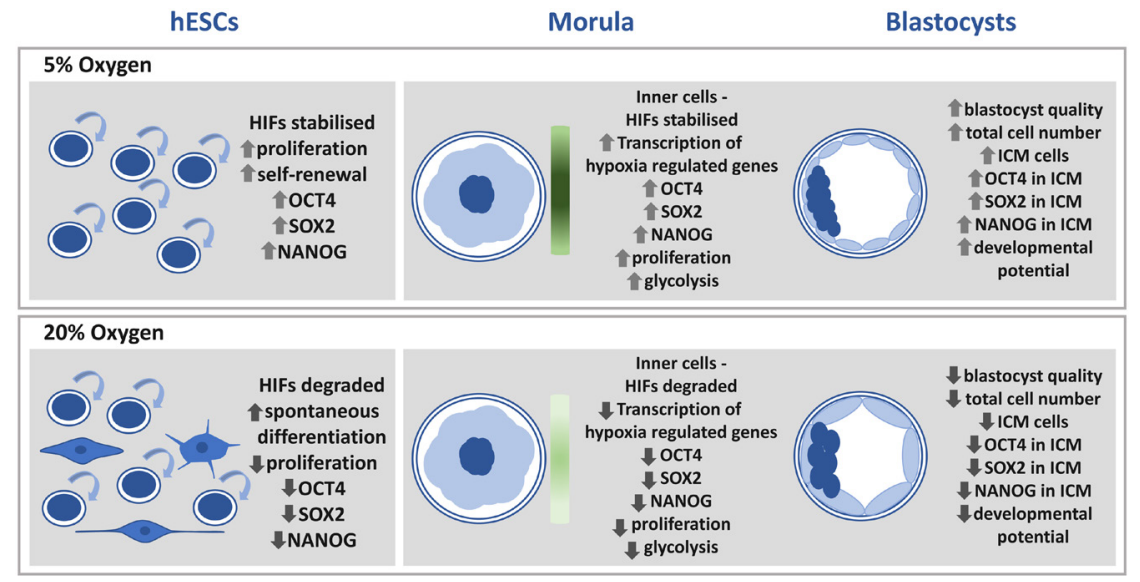

High Oxygen gradient_L Low
Figure 3 Schematic representation of the impact of environmental oxygen on hESCs and a proposed mechanism to explain the beneficial effect of culturing preimplantation embryos in hypoxic conditions. It is proposed that culturing embryos at $5 \%$ oxygen leads to increasingly hypoxic inner cells in the morula, which stabilise HIFs and increase the transcription of hypoxia regulated genes resulting in blastocysts with increased cell numbers, highly pluripotent ICMs and improved developmental competency compared to those cultured at $20 \%$ oxygen. 
contrary, mechanisms regulating the hypoxic response of hESCs would suggest that the centre of the morula being hypoxic may actually be an essential developmental phenomenon. It is proposed that hypoxic inner cells in the core of the morula will stabilise HIFs which translocate to the nucleus and increase the transcription of hypoxia regulated genes. This may provide a critical mechanism to drive the expression of OCT4, SOX2 and NANOG while simultaneously promoting proliferation and a glycolytic metabolism to ensure the blastocyst contains a wholly pluripotent ICM and hence optimal embryo development upon implantation (Fig. 3). Of course, further research will be required to verify this hypothesis. However, the proposition does highlight the importance of understanding the physiological role that environmental oxygen has on the earliest stages of embryo development as well as its implications for later life. It is proposed that recapitulating the environment of the reproductive tract in terms of nutrient availability and oxygen tension will allow in vitro embryo development to more closely replicate that in vivo, leading to improved clinical outcomes.

\section{Declaration of interest}

The author declares that there is no conflict of interest that could be perceived as prejudicing the impartiality of this review.

\section{Funding}

No funding was received to write this review, but the author's results discussed in the review were generated with funding from the Wellcome Trust, MRC, Gerald Kerkut Charitable Trust and the University of Southampton.

\section{Acknowledgement}

The author is very grateful to Professor Tom Fleming for his helpful comments on this manuscript and many insightful discussions over the years.

\section{References}

Arthur SA, Blaydes JP \& Houghton FD 2019 Glycolysis regulates human embryonic stem cell self-renewal under hypoxia through HIF-2alpha and the glycolytic sensors CTBPs. Stem Cell Reports 12 728-742. (https://doi. org/10.1016/j.stemcr.2019.02.005)

Ast T \& Mootha VK 2019 Oxygen and mammalian cell culture: are we repeating the experiment of Dr. Ox? Nature Metabolism 1 858-860. (https://doi.org/10.1038/s42255-019-0105-0)

Bahçeci M, Ciray HN, Karagenc L, Uluğ U \& Bener F 2005 Effect of oxygen concentration during the incubation of embryos of women undergoing ICSI and embryo transfer: a prospective randomized study. Reproductive Biomedicine Online 11 438-443. (https://doi.org/10.1016/s14726483(10)61136-4)

Bedaiwy MA, Falcone T, Mohamed MS, Aleem AA, Sharma RK, Worley SE, Thornton J \& Agarwal A 2004 Differential growth of human embryos in vitro: role of reactive oxygen species. Fertility and Sterility 82 593-600. (https://doi.org/10.1016/j.fertnstert.2004.02.121)

Bedaiwy MA, Mahfouz RZ, Goldberg JM, Sharma R, Falcone T, Abdel Hafez MF \& Agarwal A 2010 Relationship of reactive oxygen species levels in day 3 culture media to the outcome of in vitro fertilization/ intracytoplasmic sperm injection cycles. Fertility and Sterility $\mathbf{9 4}$ 2037-2042. (https://doi.org/10.1016/j.fertnstert.2009.12.020)

Belli M, Zhang L, Liu X, Donjacour A, Ruggeri E, Palmerini MG, Nottola SA, Macchiarelli G \& Rinaudo P 2019 Oxygen concentration alters mitochondrial structure and function in in vitro fertilized preimplantation mouse embryos. Human Reproduction 34 601-611. (https://doi.org/10.1093/humrep/dez011)

Bernardi ML, Flechon JE \& Delouis C 1996 Influence of culture system and oxygen tension on the development of ovine zygotes matured and fertilized in vitro. Journal of Reproduction and Fertility 106 161-167. (https://doi.org/10.1530/jrf.0.1060161)

Bernstein BE, Mikkelsen TS, Xie X, Kamal M, Huebert DJ, Cuff J, Fry B, Meissner A, Wernig M, Plath K et al. 2006 A bivalent chromatin structure marks key developmental genes in embryonic stem cells. Cell 125 315-326. (https://doi.org/10.1016/j.cell.2006.02.041)

Berthelot F \& Terqui M 1996 Effects of oxygen, CO2/pH and medium on the in vitro development of individually cultured porcine one- and two-cell embryos. Reproduction, Nutrition, Development 36 241-251. (https://doi.org/10.1051/rnd:19960302)

Bontekoe S, Mantikou E, Van Wely M, Seshadri S, Repping S \& Mastenbroek S 2012 Low oxygen concentrations for embryo culture in assisted reproductive technologies. Cochrane Database of Systematic Reviews Cd008950. (https://doi.org/10.1002/14651858.CD008950. pub2)

Byatt-Smith JG, Leese HJ \& Gosden RG 1991 An investigation by mathematical modelling of whether mouse and human preimplantation embryos in static culture can satisfy their demands for oxygen by diffusion. Human Reproduction 6 52-57. (https://doi.org/10.1093/ oxfordjournals.humrep.a137258)

Carmeliet P, Dor Y, Herbert JM, Fukumura D, Brusselmans K, Dewerchin M, Neeman M, Bono F, Abramovitch R, Maxwell P et al. 1998 Role of HIF1 alpha in hypoxia-mediated apoptosis, cell proliferation and tumour angiogenesis. Nature 394 485-490. (https://doi.org/10.1038/28867)

Cebral E, Carrasco I, Vantman D \& Smith R 2007 Preimplantation embryotoxicity after mouse embryo exposition to reactive oxygen species. Biocell 31 51-59. (https://doi.org/10.32604/ biocell.2007.31.051)

Childs BG, Baker DJ, Kirkland JL, Campisi J \& Van Deursen JM 2014 Senescence and apoptosis: dueling or complementary cell fates? EMBO Reports 15 1139-1153. (https://doi.org/10.15252/embr.201439245)

Christensen DR, Calder PC \& Houghton FD 2014 Effect of oxygen tension on the amino acid utilisation of human embryonic stem cells. Cellular Physiology and Biochemistry 33 237-246. (https://doi. org/10.1159/000356665)

Christensen DR, Calder PC \& Houghton FD 2015 GLUT3 and PKM2 regulate OCT4 expression and support the hypoxic culture of human embryonic stem cells. Scientific Reports 5 17500. (https://doi. org/10.1038/srep17500)

Ciray HN, Aksoy T, Yaramanci K, Karayaka I \& Bahceci M 2009 In vitro culture under physiologic oxygen concentration improves blastocyst yield and quality: a prospective randomized survey on sibling oocytes. Fertility and Sterility 91 (Supplement) 1459-1461. (https://doi. org/10.1016/j.fertnstert.2008.07.1707)

Compernolle V, Brusselmans K, Acker T, Hoet P, Tjwa M, Beck $H$, Plaisance S, Dor Y, Keshet E, Lupu F et al. 2002 Loss of HIF-2alpha and inhibition of VEGF impair fetal lung maturation, whereas treatment with VEGF prevents fatal respiratory distress in premature mice. Nature Medicine 8 702-710. (https://doi.org/10.1038/nm721)

Conaghan J, Hardy K, Leese HJ, Winston RM \& Handyside AH 1998 Culture of human preimplantation embryos to the blastocyst stage: a comparison of 3 media. International Journal of Developmental Biology 42 885-893.

Covello KL, Kehler J, Yu H, Gordan JD, Arsham AM, Hu CJ, Labosky PA, Simon MC \& Keith B 2006 HIF-2alpha regulates Oct-4: effects of hypoxia on stem cell function, embryonic development, and tumor growth. Genes and Development 20 557-570. (https://doi.org/10.1101/ gad.1399906) 
Cui XG, Han ZT, He SH, Wu XD, Chen TR, Shao CH, Chen DL, Su N, Chen YM, Wang T et al. 2017 HIF $1 / 2 \alpha$ mediates hypoxia-induced LDHA expression in human pancreatic cancer cells. Oncotarget 8 24840-24852. (https://doi.org/10.18632/oncotarget.15266)

De Munck N, Janssens R, Segers I, Tournaye H, Van De Velde H \& Verheyen G 2019 Influence of ultra-low oxygen (2\%) tension on invitro human embryo development. Human Reproduction 34 228-234. (https://doi.org/10.1093/humrep/dey370)

Devreker F, Hardy K, Van Den Bergh M, Vannin AS, Emiliani S \& Englert Y 2001 Amino acids promote human blastocyst development in vitro. Human Reproduction 16 749-756. (https://doi.org/10.1093/ humrep/16.4.749)

Dumoulin JC, Vanvuchelen RC, Land JA, Pieters MH, Geraedts JP \& Evers JL 1995 Effect of oxygen concentration on in vitro fertilization and embryo culture in the human and the mouse. Fertility and Sterility 63 115-119. (https://doi.org/10.1016/s0015-0282(16)57305-1)

Dumoulin JC, Meijers CJ, Bras M, Coonen E, Geraedts JP \& Evers JL 1999 Effect of oxygen concentration on human in-vitro fertilization and embryo culture. Human Reproduction 14 465-469. (https://doi. org/10.1093/humrep/14.2.465)

Edwards RG, Steptoe PC \& Purdy JM 1970 Fertilization and cleavage in vitro of preovulator human oocytes. Nature 227 1307-1309. (https://doi. org/10.1038/2271307a0)

Ema M, Taya S, Yokotani N, Sogawa K, Matsuda Y \& Fujii-Kuriyama Y 1997 A novel bHLH-PAS factor with close sequence similarity to hypoxiainducible factor 1alpha regulates the VEGF expression and is potentially involved in lung and vascular development. PNAS 94 4273-4278. (https://doi.org/10.1073/pnas.94.9.4273)

Ezashi T, Das P \& Roberts RM 2005 Low O2 tensions and the prevention of differentiation of hES cells. PNAS 102 4783-4788. (https://doi. org/10.1073/pnas.0501283102)

Fischer B \& Bavister BD 1993 Oxygen tension in the oviduct and uterus of rhesus monkeys, hamsters and rabbits. Journal of Reproduction and Fertility 99 673-679. (https://doi.org/10.1530/jrf.0.0990673)

Fischer-Brown A, Monson R, Parrish J \& Rutledge J 2002 Cell allocation in bovine embryos cultured in two media under two oxygen concentrations. Zygote 10 341-348. (https://doi.org/10.1017/s0967199402004082)

Flamme I, Krieg M \& Plate KH 1998 Up-regulation of vascular endothelial growth factor in stromal cells of hemangioblastomas is correlated with up-regulation of the transcription factor HRF/HIF-2alpha. American Journal of Pathology 153 25-29. (https://doi.org/10.1016/s00029440(10)65541-1)

Forristal CE, Wright KL, Hanley NA, Oreffo RO \& Houghton FD 2010 Hypoxia inducible factors regulate pluripotency and proliferation in human embryonic stem cells cultured at reduced oxygen tensions. Reproduction 139 85-97. (https://doi.org/10.1530/REP-09-0300)

Forristal CE, Christensen DR, Chinnery FE, Petruzzelli R, Parry KL, Sanchez-Elsner T \& Houghton FD 2013 Environmental oxygen tension regulates the energy metabolism and self-renewal of human embryonic stem cells. PLOS ONE 8 e62507. (https://doi.org/10.1371/journal. pone.0062507)

Forsyth NR, Musio A, Vezzoni P, Simpson AH, Noble BS \& Mcwhir J 2006 Physiologic oxygen enhances human embryonic stem cell clonal recovery and reduces chromosomal abnormalities. Cloning and Stem Cells 8 16-23. (https://doi.org/10.1089/clo.2006.8.16)

Fujitani Y, Kasai K, Ohtani S, Nishimura K, Yamada M \& Utsumi K 1997 Effect of oxygen concentration and free radicals on in vitro development of in vitro-produced bovine embryos. Journal of Animal Science $\mathbf{7 5}$ 483-489. (https://doi.org/10.2527/1997.752483x)

Goda N \& Kanai M 2012 Hypoxia-inducible factors and their roles in energy metabolism. International Journal of Hematology 95 457-463. (https://doi.org/10.1007/s12185-012-1069-y)

Goto Y, Noda Y, Mori T \& Nakano M 1993 Increased generation of reactive oxygen species in embryos cultured in vitro. Free Radical Biology and Medicine 15 69-75. (https://doi.org/10.1016/0891-5849(93)90126-f)

Gu YZ, Moran SM, Hogenesch JB, Wartman L \& Bradfield CA 1998 Molecular characterization and chromosomal localization of a third alpha-class hypoxia inducible factor subunit, HIF3alpha. Gene Expression 7 205-213.

Gu W, Gaeta X, Sahakyan A, Chan AB, Hong CS, Kim R, Braas D, Plath K, Lowry WE \& Christofk HR 2016 Glycolytic metabolism plays a functional role in regulating human pluripotent stem cell state. Cell Stem Cell 19 476-490. (https://doi.org/10.1016/j.stem.2016.08.008)

Guo N, Li Y, Ai J, Gu L, Chen W \& Liu Q 2014 Two different concentrations of oxygen for culturing precompaction stage embryos on human embryo development competence: a prospective randomized sibling-oocyte study. International Journal of Clinical and Experimental Pathology 7 6191-6198.

Hara S, Hamada J, Kobayashi C, Kondo Y \& Imura N 2001 Expression and characterization of hypoxia-inducible factor (HIF)-3alpha in human kidney: suppression of HIF-mediated gene expression by HIF-3alpha. Biochemical and Biophysical Research Communications 287 808-813. (https://doi.org/10.1006/bbrc.2001.5659)

Harlow GM \& Quinn P 1979 Foetal and placental growth in the mouse after pre-implantation development in vitro under oxygen concentrations of 5 and 20\%. Australian Journal of Biological Sciences 32 363-369. (https:// doi.org/10.1071/bi9790363)

Harvey AJ, Kind KL, Pantaleon M, Armstrong DT \& Thompson JG 2004 Oxygen-regulated gene expression in bovine blastocysts. Biology of Reproduction 71 1108-1119. (https://doi.org/10.1095/ biolreprod.104.028639)

Harvey AJ, Kind KL \& Thompson JG 2007 Regulation of gene expression in bovine blastocysts in response to oxygen and the iron chelator desferrioxamine. Biology of Reproduction 77 93-101. (https://doi. org/10.1095/biolreprod.106.058826)

Harvey AJ, Rathjen J, Yu LJ \& Gardner DK 2016 Oxygen modulates human embryonic stem cell metabolism in the absence of changes in selfrenewal. Reproduction, Fertility, and Development 28 446-458. (https:// doi.org/10.1071/RD14013)

Heikkila M, Pasanen A, Kivirikko KI \& Myllyharju J 2011 Roles of the human hypoxia-inducible factor (HIF)-3alpha variants in the hypoxia response. Cellular and Molecular Life Sciences 68 3885-3901. (https:// doi.org/10.1007/s00018-011-0679-5)

Hillman N \& Tasca RJ 1969 Ultrastructural and autoradiographic studies of mouse cleavage stages. American Journal of Anatomy 126 151-173. (https://doi.org/10.1002/aja.1001260203)

Holmquist-Mengelbier L, Fredlund E, Löfstedt T, Noguera R, Navarro $S$, Nilsson H, Pietras A, Vallon-Christersson J, Borg A, Gradin K et al. 2006 Recruitment of HIF-1alpha and HIF-2alpha to common target genes is differentially regulated in neuroblastoma: HIF-2alpha promotes an aggressive phenotype. Cancer Cell 10 413-423. (https://doi. org/10.1016/j.ccr.2006.08.026)

Houghton FD 2006 Energy metabolism of the inner cell mass and trophectoderm of the mouse blastocyst. Differentiation: Research in Biological Diversity $\mathbf{7 4}$ 11-18. (https://doi.org/10.1111/j.1432-0436.2006.00052.x)

Hu CJ, Wang LY, Chodosh LA, Keith B \& Simon MC 2003 Differential roles of hypoxia-inducible factor 1alpha (HIF-1alpha) and HIF-2alpha in hypoxic gene regulation. Molecular and Cellular Biology 23 9361-9374. (https://doi.org/10.1128/mcb.23.24.9361-9374.2003)

lyer NV, Kotch LE, Agani F, Leung SW, Laughner E, Wenger RH, Gassmann M, Gearhart JD, Lawler AM, Yu AY et al. 1998 Cellular and developmental control of $\mathrm{O} 2$ homeostasis by hypoxia-inducible factor 1 alpha. Genes and Development 12 149-162. (https://doi.org/10.1101/ gad.12.2.149)

Karagenc L, Sertkaya Z, Ciray N, Ulug U \& Bahceci M 2004 Impact of oxygen concentration on embryonic development of mouse zygotes. Reproductive Biomedicine Online 9 409-417. (https://doi.org/10.1016/ s1472-6483(10)61276-x)

Karja NW, Wongsrikeao P, Murakami M, Agung B, Fahrudin M, Nagai T \& Otoi T 2004 Effects of oxygen tension on the development and quality of porcine in vitro fertilized embryos. Theriogenology 62 1585-1595. (https://doi.org/10.1016/j.theriogenology.2004.03.012)

Kaser DJ, Bogale B, Sarda V, Farland LV, Williams PL \& Racowsky C 2018 Randomized controlled trial of low $(5 \%)$ versus ultralow $(2 \%)$ oxygen for extended culture using bipronucleate and tripronucleate human preimplantation embryos. Fertility and Sterility 109 1030.e2-1037.e2. (https://doi.org/10.1016/j.fertnstert.2018.02.119)

Kasterstein E, Strassburger D, Komarovsky D, Bern O, Komsky A, Raziel A, Friedler S \& Ron-El R 2013 The effect of two distinct levels of oxygen concentration on embryo development in a sibling oocyte study. Journal of Assisted Reproduction and Genetics 30 1073-1079. (https://doi. org/10.1007/s10815-013-0032-z) 
Katz-Jaffe MG, Linck DW, Schoolcraft WB \& Gardner DK 2005 A proteomic analysis of mammalian preimplantation embryonic development. Reproduction 130 899-905. (https://doi.org/10.1530/rep.1.00854)

Kelley RL \& Gardner DK 2016 Combined effects of individual culture and atmospheric oxygen on preimplantation mouse embryos in vitro. Reproductive Biomedicine Online 33 537-549. (https://doi. org/10.1016/j.rbmo.2016.08.003)

Kelley RL \& Gardner DK 2019 Individual culture and atmospheric oxygen during culture affect mouse preimplantation embryo metabolism and post-implantation development. Reproductive Biomedicine Online 39 3-18. (https://doi.org/10.1016/j.rbmo.2019.03.102)

Kirkegaard K, Hindkjaer JJ \& Ingerslev HJ 2013 Effect of oxygen concentration on human embryo development evaluated by timelapse monitoring. Fertility and Sterility 99 738-744.e4. (https://doi. org/10.1016/j.fertnstert.2012.11.028)

Kitagawa Y, Suzuki K, Yoneda A \& Watanabe T 2004 Effects of oxygen concentration and antioxidants on the in vitro developmental ability, production of reactive oxygen species (ROS), and DNA fragmentation in porcine embryos. Theriogenology 62 1186-1197. (https://doi. org/10.1016/j.theriogenology.2004.01.011)

Koh MY, Lemos R, Liu X \& Powis G 2011 The hypoxia-associated factor switches cells from HIF- $1 \alpha$ - to HIF- $2 \alpha$-dependent signaling promoting stem cell characteristics, aggressive tumor growth and invasion. Cancer Research 71 4015-4027. (https://doi.org/10.1158/0008-5472.CAN-104142)

Kotch LE, lyer NV, Laughner E \& Semenza GL 1999 Defective vascularization of HIF-1alpha-null embryos is not associated with VEGF deficiency but with mesenchymal cell death. Developmental Biology 209 254-267. (https://doi.org/10.1006/dbio.1999.9253)

Kovacic B \& Vlaisavljevic V 2008 Influence of atmospheric versus reduced oxygen concentration on development of human blastocysts in vitro: a prospective study on sibling oocytes. Reproductive Biomedicine Online 17 229-236. (https://doi.org/10.1016/s1472-6483(10)60199-x)

Lane M \& Gardner DK 1994 Increase in postimplantation development of cultured mouse embryos by amino acids and induction of fetal retardation and exencephaly by ammonium ions. Journal of Reproduction and Fertility 102 305-312. (https://doi.org/10.1530/jrf.0.1020305)

Leite RF, Annes K, Ispada J, de Lima CB, Dos Santos ÉC, Fontes PK, Nogueira MFG \& Milazzotto MP 2017 Oxidative stress alters the profile of transcription factors related to early development on in vitro produced embryos. Oxidative Medicine and Cellular Longevity 20171502489. (https://doi.org/10.1155/2017/1502489)

Lengner CJ, Gimelbrant AA, Erwin JA, Cheng AW, Guenther MG, Welstead GG, Alagappan R, Frampton GM, Xu P, Muffat J et al. 2010 Derivation of pre- $X$ inactivation human embryonic stem cells under physiological oxygen concentrations. Cell 141 872-883. (https://doi. org/10.1016/j.cell.2010.04.010)

Li J \& Foote RH 1993 Culture of rabbit zygotes into blastocysts in proteinfree medium with one to twenty per cent oxygen. Journal of Reproduction and Fertility 98 163-167. (https://doi.org/10.1530/jrf.0.0980163)

Li W, Goossens K, Van Poucke M, Forier K, Braeckmans K, Van Soom A \& Peelman LJ 2016 High oxygen tension increases global methylation in bovine 4-cell embryos and blastocysts but does not affect general retrotransposon expression. Reproduction, Fertility, and Development 28 948-959. (https://doi.org/10.1071/RD14133)

Lim JM, Reggio BC, Godke RA \& Hansel W 1999 Development of invitro-derived bovine embryos cultured in 5\% CO2 in air or in 5\% O2, 5\% CO2 and 90\% N2. Human Reproduction 14 458-464. (https://doi. org/10.1093/humrep/14.2.458)

Ludwig TE, Levenstein ME, Jones JM, Berggren WT, Mitchen ER, Frane JL, Crandall LJ, Daigh CA, Conard KR, Piekarczyk MS et al. 2006 Derivation of human embryonic stem cells in defined conditions. Nature Biotechnology 24 185-187. (https://doi.org/10.1038/nbt1177)

Ma YY, Chen HW \& Tzeng CR 2017 Low oxygen tension increases mitochondrial membrane potential and enhances expression of antioxidant genes and implantation protein of mouse blastocyst cultured in vitro. Journal of Ovarian Research 10 47. (https://doi.org/10.1186/ s13048-017-0344-1)

Makino Y, Cao R, Svensson K, Bertilsson G, Asman M, Tanaka H, Cao Y, Berkenstam A \& Poellinger L 2001 Inhibitory PAS domain protein is a negative regulator of hypoxia-inducible gene expression. Nature $\mathbf{4 1 4}$ 550-554. (https://doi.org/10.1038/35107085)
Martin KL \& Leese HJ 1999 Role of developmental factors in the switch from pyruvate to glucose as the major exogenous energy substrate in the preimplantation mouse embryo. Reproduction, Fertility, and Development 11 425-433. (https://doi.org/10.1071/rd97071)

Maxwell PH, Dachs GU, Gleadle JM, Nicholls LG, Harris AL, Stratford IJ, Hankinson O, Pugh CW \& Ratcliffe PJ 1997 Hypoxia-inducible factor-1 modulates gene expression in solid tumors and influences both angiogenesis and tumor growth. PNAS 94 8104-8109. (https://doi. org/10.1073/pnas.94.15.8104)

Meintjes M, Chantilis SJ, Douglas JD, Rodriguez AJ, Guerami AR, Bookout DM, Barnett BD \& Madden JD 2009 A controlled randomized trial evaluating the effect of lowered incubator oxygen tension on live births in a predominantly blastocyst transfer program. Human Reproduction 24 300-307. (https://doi.org/10.1093/humrep/den368)

Meuter A, Rogmann LM, Winterhoff BJ, Tchkonia T, Kirkland JL \& Morbeck DE 2014 Markers of cellular senescence are elevated in murine blastocysts cultured in vitro: molecular consequences of culture in atmospheric oxygen. Journal of Assisted Reproduction and Genetics 31 1259-1267. (https://doi.org/10.1007/s10815-014-0299-8)

Mingoti GZ, Castro VS, Méo SC, LS, Sá Barretto LS \& Garcia JM 2011 The effects of macromolecular and serum supplements and oxygen tension during bovine in vitro procedures on kinetics of oocyte maturation and embryo development. In Vitro Cellular and Developmental Biology: Animal 47 361-367. (https://doi.org/10.1007/s11626-011-9400-0)

Mole DR, Blancher C, Copley RR, Pollard PJ, Gleadle JM, Ragoussis J \& Ratcliffe PJ 2009 Genome-wide association of hypoxia-inducible factor (HIF)-1alpha and HIF-2alpha DNA binding with expression profiling of hypoxia-inducible transcripts. Journal of Biological Chemistry 284 16767-16775. (https://doi.org/10.1074/jbc.M901790200)

Nguyen AQ, Bardua I, Greene B, Wrenzycki C, Wagner U \& Ziller V 2020 Mouse embryos exposed to oxygen concentrations that mimic changes in the oviduct and uterus show improvement in blastocyst rate, blastocyst size, and accelerated cell division. Reproductive Biology 20 147-153. (https://doi.org/10.1016/j.repbio.2020.03.011)

Olson SE \& Seidel Jr GE 2000 Reduced oxygen tension and EDTA improve bovine zygote development in a chemically defined medium. Journal of Animal Science 78 152-157. (https://doi.org/10.2527/2000.781152x)

Ottosen LD, Hindkaer J, Husth M, Petersen DE, Kirk J \& Ingerslev HJ 2006 Observations on intrauterine oxygen tension measured by fibre-optic microsensors. Reproductive Biomedicine Online 13 380-385. (https:// doi.org/10.1016/s1472-6483(10)61443-5)

Pabon JE, Findley WE \& Gibbons WE 1989 The toxic effect of short exposures to the atmospheric oxygen concentration on early mouse embryonic development. Fertility and Sterility 51 896-900. (https://doi. org/10.1016/s0015-0282(16)60688-x)

Petruzzelli R, Christensen DR, Parry KL, Sanchez-Elsner T \& Houghton FD 2014 HIF-2alpha regulates NANOG expression in human embryonic stem cells following hypoxia and reoxygenation through the interaction with an Oct-Sox cis regulatory element. PLOS ONE 9 e108309. (https:// doi.org/10.1371/journal.pone.0108309)

Prasad SM, Czepiel M, Cetinkaya C, Smigielska K, Weli SC, Lysdahl H, Gabrielsen A, Petersen K, Ehlers N, Fink T et al. 2009 Continuous hypoxic culturing maintains activation of Notch and allows long-term propagation of human embryonic stem cells without spontaneous differentiation. Cell Proliferation 42 63-74. (https://doi.org/10.1111/ j.1365-2184.2008.00571.x)

Quinn P \& Harlow GM 1978 The effect of oxygen on the development of preimplantation mouse embryos in vitro. Journal of Experimental Zoology 206 73-80. (https://doi.org/10.1002/jez.1402060108)

Quintana DD, Garcia JA, Sarkar SN, Jun S, Engler-Chiurazzi EB, Russell AE, Cavendish JZ \& Simpkins JW 2019 Hypoxia-reoxygenation of primary astrocytes results in a redistribution of mitochondrial size and mitophagy. Mitochondrion 47 244-255. (https://doi.org/10.1016/j. mito.2018.12.004)

Ramírez-Bergeron DL, Runge A, Adelman DM, Gohil M \& Simon MC 2006 HIF-dependent hematopoietic factors regulate the development of the embryonic vasculature. Developmental Cell 11 81-92. (https://doi. org/10.1016/j.devcel.2006.04.018)

Rinaudo PF, Giritharan G, Talbi S, Dobson AT \& Schultz RM 2006 Effects of oxygen tension on gene expression in preimplantation mouse embryos. Fertility and Sterility 86 (Supplement) 1252-1265, 1265.e1-36. (https:// doi.org/10.1016/j.fertnstert.2006.05.017) 
Rogers PA, Murphy CR, Rogers AW \& Gannon BJ 1983 Capillary patency and permeability in the endometrium surrounding the implanting rat blastocyst. International Journal of Microcirculation, Clinical and Experimental 2 241-249.

Ruiz M, Santamaria-Lopez E, Blasco V, Hernaez MJ, Caligara C, Pellicer A, Fernandez-Sanchez M \& Prados N 2020 Effect of group embryo culture under low-oxygen tension in benchtop incubators on human embryo culture: prospective, randomized, controlled trial. Reproductive Sciences 27 1522-1533. (https://doi.org/10.1007/s43032-020-00150-5)

Semenza GL 1998 Hypoxia-inducible factor 1: master regulator of O2 homeostasis. Current Opinion in Genetics and Development 8 588-594. (https://doi.org/10.1016/s0959-437x(98)80016-6)

Semenza GL \& Wang GL 1992 A nuclear factor induced by hypoxia via de novo protein synthesis binds to the human erythropoietin gene enhancer at a site required for transcriptional activation. Molecular and Cellular Biology 12 5447-5454. (https://doi.org/10.1128/mcb.12.12.5447)

Skiles WM, Kester A, Pryor JH, Westhusin ME, Golding MC \& Long CR 2018 Oxygen-induced alterations in the expression of chromatin modifying enzymes and the transcriptional regulation of imprinted genes. Gene Expression Patterns 28 1-11. (https://doi.org/10.1016/j. gep.2018.01.001)

Steptoe PC \& Edwards RG 1978 Birth after the reimplantation of a human embryo. Lancet 2 366. (https://doi.org/10.1016/s0140-6736(78)929574)

Steptoe PC, Edwards RG \& Purdy JM 1971 Human blastocysts grown in culture. Nature 229 132-133. (https://doi.org/10.1038/229132a0)

Stern S, Biggers JD \&Anderson E 1971 Mitochondria and early development of the mouse. Journal of Experimental Zoology 176 179-191. (https://doi. org/10.1002/jez.1401760206)

Takahashi M 2012 Oxidative stress and redox regulation on in vitro development of mammalian embryos. Journal of Reproduction and Development 58 1-9. (https://doi.org/10.1262/jrd.11-138n)

Takahashi M, Keicho K, Takahashi H, Ogawa H, Schultz RM \& Okano A 2000 Effect of oxidative stress on development and DNA damage in in-vitro cultured bovine embryos by comet assay. Theriogenology $\mathbf{5 4}$ 137-145. (https://doi.org/10.1016/s0093-691x(00)00332-0)

Thompson JG, Simpson AC, Pugh PA, Donnelly PE \& Tervit HR 1990 Effect of oxygen concentration on in-vitro development of preimplantation sheep and cattle embryos. Journal of Reproduction and Fertility 89 573-578. (https://doi.org/10.1530/jrf.0.0890573)

Tian H, Mcknight SL \& Russell DW 1997 Endothelial PAS domain protein 1 (EPAS1), a transcription factor selectively expressed in endothelial cells. Genes and Development 11 72-82. (https://doi.org/10.1101/ gad.11.1.72)
Tian H, Hammer RE, Matsumoto AM, Russell DW \& Mcknight SL 1998 The hypoxia-responsive transcription factor EPAS1 is essential for catecholamine homeostasis and protection against heart failure during embryonic development. Genes and Development 12 3320-3324. (https://doi.org/10.1101/gad.12.21.3320)

Van Montfoort APA, Arts EGJM, Wijnandts L, Sluijmer A, Pelinck MJ, Land JA \& Van Echten-Arends J 2020 Reduced oxygen concentration during human IVF culture improves embryo utilization and cumulative pregnancy rates per cycle. Human Reproduction Open 2020 hoz036. (https://doi.org/10.1093/hropen/hoz036)

Wale PL \& Gardner DK 2012 Oxygen regulates amino acid turnover and carbohydrate uptake during the preimplantation period of mouse embryo development. Biology of Reproduction 87 24, 1-8. (https://doi. org/10.1095/biolreprod.112.100552)

Wale PL \& Gardner DK 2013 Oxygen affects the ability of mouse blastocysts to regulate ammonium. Biology of Reproduction 8975. (https://doi.org/10.1095/biolreprod.113.109256)

Wang GL, Jiang BH, Rue EA \& Semenza GL 1995 Hypoxia-inducible factor 1 is a basic-helix-loop-helix-PAS heterodimer regulated by cellular O2 tension. PNAS 92 5510-5514. (https://doi.org/10.1073/ pnas.92.12.5510)

Whitten WK 1969 The effect of oxygen on cleavage of mouse eggs. In Abstracts of 2nd Annual Meeting of the Society for the Study of Reproduction, Davies, California, p. 29.

Whitten WK 1971 Nutrient requirements for the culture of preimplantation embryos in vitro. Advances in the Biosciences 6 129-141. (https://doi. org/10.1016/B978-0-08-017571-3.50013-9)

Wiesener MS, Jürgensen JS, Rosenberger C, Scholze CK, Hörstrup JH, Warnecke C, Mandriota S, Bechmann I, Frei UA, Pugh CW et al. 2003 Widespread hypoxia-inducible expression of HIF-2alpha in distinct cell populations of different organs. FASEB Journal 17 271-273. (https://doi. org/10.1096/fj.02-0445fje)

Yoshida Y, Takahashi K, Okita K, Ichisaka T \& Yamanaka S 2009 Hypoxia enhances the generation of induced pluripotent stem cells. Cell Stem Cell 5 237-241. (https://doi.org/10.1016/j.stem.2009.08.001)

Received 18 June 2020

First decision 20 August 2020

Revised Manuscript received 3 November 2020

Accepted 24 November 2020 